\title{
Paired arbuscules in the Arum-type arbuscular mycorrhizal symbiosis with Linum usitatissimum
}

\author{
Sandy Dickson, Peter Schweiger, F. Andrew Smith, Bengt Söderström, and \\ Sally Smith
}

\begin{abstract}
Experiments were conducted to investigate the "paired" arbuscules characteristic of Arum-type mycorrhizal colonization in Linum usitatissimum L. The development and senescence of arbuscular structures were followed in a time course study. Roots were freeze-sectioned longitudinally and mycorrhizal structures visualized using nitroblue tetrazolium, a vital stain to indicate metabolically active arbuscules and intercellular hyphae, followed by acid fuchsin counterstaining. Arbuscules were imaged using laser scanning confocal microscopy. The volume and surface area of each arbuscule of a developing paired structure were measured using three-dimensional imaging software. Arbuscules occurred in pairs in adjacent cortical cells arising from a single, radial intercellular hypha. These "paired" arbuscules often appeared to be at different developmental stages. Logistic regression and measurement of surface area indicated that there was a delay in initiation of the second arbuscule.
\end{abstract}

Key words: Arum-type arbuscular mycorrhiza, double staining, metabolic activity, morphology, confocal microscopy, Linum usitatissimum.

\begin{abstract}
Résumé : Les auteurs ont conduit des essais afin d'étudier les arbuscules «jumelés » caractéristiques de la mycorhization de type Arum, chez le Linum usitatissimum L. Pour suivre les chronoséquences du développement et de la sénescence de ces structures arbusculaires, ils ont cryo-sectionné longitudinalement les racines et ils ont visualisé les structures mycorhiziennes à l'aide du nitro-bleu de tétrazolium, un colorant vital indiquant les arbuscules et les hyphes intercellulaires actifs, suivi d'une contre-coloration à la fuschine acide. Les images des arbuscules ont été observées par microscopie confocale au laser. Les auteurs ont mesuré le volume et l'aire de chaque arbuscule d'une structure jumelée en développement, à l'aide d'un logiciel d'imagerie à trois dimensions. On retrouve les arbuscules en paires, dans des cellules corticales adjacentes, en provenance d'un hyphe radial intercellulaire unique. Ces arbuscules "jumelés » semblent souvent être à des stades différents de développement. La régression logistique et les mesures de l'aire indiquent qu'il y a un délai dans l'initiation du second arbuscule.
\end{abstract}

Mots clés : mycorhize arbusculaire de type Arum, double coloration, activité métabolique, morphologie, microscopie confocale, Linum usitatissimum.

[Traduit par la Rédaction]

\section{Introduction}

The majority of terrestrial plant species form mycorrhizal symbiotic associations, most commonly with arbuscular mycorrhizal (AM) fungi (Smith and Read 1997). Two major structural classes of AM symbiosis, Arum types and Paris types, have been identified from fungal morphological differences observed in host plant roots (Gallaud 1905). Many detailed studies have been conducted on fungal morphology

Received 8 October 2002. Published on the NRC Research Press Web site at http://canjbot.nrc.ca on 23 May 2003.

S. Dickson, ${ }^{1}$ F.A. Smith, and S. Smith. Department of Soil and Water and The Centre for Plant Root Symbioses, The University of Adelaide, Waite Campus, PMB 1,

Glen Osmond, South Australia 5064, Australia.

P. Schweiger ${ }^{2}$ and B. Söderström. Department of Microbial Ecology, Ecology Building, Lund University, S-223 62 Lund, Sweden.

${ }^{1}$ Corresponding author (sandy.dickson@adelaide edu.au).

${ }^{2}$ Present address: Institute of Ecology and Conservation Biology, Vienna University, A-1090 Vienna, Austria. of both Arum-type (e.g., Toth and Miller 1984; Brundrett et al. 1985; Alexander et al. 1988; Rosewarne et al. 1997) and Paris-type colonization (Brundrett and Kendrick 1990; Cooke et al. 1993; Whitbread et al. 1996; Cavagnaro et al. 2001a). Intermediate types have also been observed with both inter- and intracellular hyphae and arbuscules (see Smith and Smith 1997 and references therein). Little variation has been shown in the arbuscule formation of Arumtype AM, which consists of a single terminal arbuscule in a cortical cell apparently arising from a lateral branch of a longitudinal intercellular hypha (see Gallaud 1905).

The use of double staining with a solution containing nitroblue tetrazolium (Kough et al. 1987) followed by counterstaining with acid fuchsin (Kormanik and McGraw 1982) allows metabolically active mycorrhizal structures to be observed in combination with inactive structures. The dual-staining technique has been used to measure active root colonization, the rates of nutrient transfer from fungus to plant, and the developmental time sequence of the arbuscule (Schaffer and Peterson 1993; Smith et al. 1994; Dickson et al. 1999; Dickson and Smith 2001).

This paper reports on the colonization observed in three 
cultivars of Linum usitatissimum L., an important agricultural crop plant that shows intercellular hyphae and arbuscules characteristic of Arum-type colonization. However, in this plant, arbuscules occur in pairs in adjacent longitudinally arrayed cortical cells arising from a single, radial intercellular hypha. These "paired" arbuscules were investigated using double staining and laser scanning confocal microscopy to determine their developmental cycle and structure.

\section{Materials and methods}

Two experiments were conducted. Experiment 1 identified the colonization patterns of different AM fungi in three L. usitatissimum cultivars (Linetta, Eyre (known as Linola $^{\mathrm{TM}}$, trademark of CSIRO Division of Plant Industry, Canberra, A.C.T.), and Glenelg). Experiment 2 examined the development of arbuscules of Glomus intraradices Schenck \& Smith and their metabolic activity (indicated by their succinate dehydrogenase activity) over time using two L. usitatissimum cultivars (Eyre and Glenelg).

\section{Experiment 1}

Four species of AM fungi were pot cultured with subterranean clover (Trifolium subterraneum L. cv. Mount Barker) as the host plant. The fungi were Gigaspora rosea Nicolson \& Schenck (BEG 9), Scutellospora calospora (Nicol. \& Gerd.) Walker \& Sanders (BEG 43), Glomus mosseae (Nicol. \& Gerd.) Gerd. \& Trappe (BEG 84), and Glomus intraradices (BEG 87). Starter inoculum was kindly provided by Dr. Iver Jakobsen, Ris $\varnothing$ National Laboratory, Denmark.

The soil mix used was an infertile, acidic sandy loam mixed 1:1 (v/v) with quartz sand to which $\mathrm{CaCO}_{3}$ had been added to raise the $\mathrm{pH}$ to $6\left(0.01 \mathrm{M} \mathrm{CaCl}_{2}\right)$. A complete set of basal nutrients except phosphorus was added to the soil mix at the following concentrations (milligrams per kilogram): $\mathrm{NH}_{4} \mathrm{NO}_{3}, 65 ; \mathrm{K}_{2} \mathrm{SO}_{4}, 71 ; \mathrm{CaCl}_{2}, 71 ; \mathrm{CuSO}_{4} \cdot 5 \mathrm{H}_{2} \mathrm{O}, 2$; $\mathrm{ZnSO}_{4} \cdot 7 \mathrm{H}_{2} \mathrm{O}, 10 ; \mathrm{MnSO}_{4} \cdot \mathrm{H}_{2} \mathrm{O}, 10 ; \operatorname{CoSO}_{4} \cdot 7 \mathrm{H}_{2} \mathrm{O}, 0.35$; $\mathrm{NaMoO}_{4} \cdot 2 \mathrm{H}_{2} \mathrm{O}, 0.18 ; \mathrm{MgSO}_{4} \cdot 7 \mathrm{H}_{2} \mathrm{O}, 20$. Pregerminated clover seeds were sown into the 2.5 -L pots and kept in a greenhouse $\left(20 / 16^{\circ} \mathrm{C}\right.$ day/night temperature with a relative humidity of approximately 70\%). Daylight lamps supplemented ambient daylight to give a $16 \mathrm{~h}: 8 \mathrm{~h}$ light-dark cycle. After 3 weeks of growth, three seedlings of L. usitatissimum of each of the three cultivars were planted between the clover plants. After an additional 3 weeks, the seedlings were harvested and subsamples taken for sectioning or determination of percent colonization by the AM fungi.

Roots were sectioned using a method modified from Smith and Dickson (1991). Root segments were embedded into gelatine blocks and cut into $120-\mu \mathrm{m}$-thick longitudinal sections using a freezing microtome. Sections were then placed overnight into a solution of nitroblue tetrazolium with appropriate reagents to indicate succinate dehydrogenase activity (Schaffer and Peterson 1993) followed by transfer to $0.01 \%(\mathrm{w} / \mathrm{v})$ acid fuchsin in lactoglycerol (lactic acid glycerol - water, 1:1:1). After, an additional $24 \mathrm{~h}$ sections were rinsed with deionized water and either mounted onto slides or stored in $100 \%$ glycerol.
A Leica DM RBE laser scanning confocal microscope equipped with an argon-krypton laser was used to visualize mycorrhizal structures within the root sections. Samples were observed using a $63 \times$ water immersion objective (PL APO, NA 1.20). The excitation wavelength was set at $568 \mathrm{~nm}$ and fluorescence emission passed through a 590-nm-long pass filter. The pinhole size, gain, and photomultiplier tube signal amplification were adjusted manually. Most images were further magnified by electronic zoom. A series of optical $x y$ slices were collected at $1-\mu \mathrm{m}$ intervals, which was corrected to $0.71 \mu \mathrm{m}$ to allow for axial distortion of the immersion and mounting media (see Dickson and Kolesik 1999). Confocal images were recorded and stored as Leica files.

Files were converted into a format useable with Confocal Assistant version $4.02^{\circ}$ (Todd Clark Brelje, free software from website http://www.biol.sc.edu/resource/confocal.html) and Adobe Photoshop ${ }^{\circledR}$ (Adobe Systems Incorporated, San Jose, Calif.). Individual optical slices were merged to produce extended focus images. The volume of each arbuscular structure was measured and surface area calculated using Volume J (National Institutes of Health, Bethesda, Md.) with a threshold setting of 60 .

\section{Experiment 2}

A nurse tray system modified from nurse pots (Brundrett et al. 1985; Rosewarne et al. 1997) was used to produce plants for a time course experiment. The soil mix and growth conditions used have been previously described (Dickson and Smith 2001). Two nurse trays were established with Allium porrum L. cv. Vertina colonized by Glomus intraradices (DAOM 181602). The fungus was subcultured from an axenic culture on transformed roots obtained from Prof. J.A. Fortin, University of Montreal, Montreal, Que., Canada. The plants were grown for 6 weeks before pregerminated seedlings of $L$. usitatissimum $\mathrm{cv}$. Eyre and cv. Glenelg were planted into the trays. The plants were grown in a glasshouse with a mean temperature of $22^{\circ} \mathrm{C}$ day to $14^{\circ} \mathrm{C}$ night and light levels in the range of 250$1100 \mu \mathrm{mol} \cdot \mathrm{m}^{-2} \cdot \mathrm{s}^{-1}$. Two replicates of each cultivar were harvested every day for 3-16 days. The entire root systems were sectioned and stained as described in Dickson and Smith (2001). Sections were examined using light microscopy and the metabolic activity of arbuscules was recorded.

\section{Statistical analysis}

Statistical analyses (logistic regression) were performed using the JMP IN 4 statistical package (SAS Institute Inc., Cary, N.C.). Data from two replicate plants from each of two L. usitatissimum cultivars, Eyre and Glenelg, were combined to produce the predicted probabilities for the metabolic activity in the paired arbuscular structures.

\section{Results}

\section{Examination of colonization patterns}

After 3 weeks in the established pot cultures, all L. usitatissimum plants in Experiment 1 were colonized (results not shown). Colonization was of the Arum type with intercellular hyphae and arbuscules. All four fungi formed the majority of arbuscules as longitudinal pairs in adjacent cortical cells. Double staining showed that these paired 
Table 1. Incidence of different metabolic status in twin arbuscular units of Glomus intraradices for four replicates (R) of Linum usitatissimum cultivars.

\begin{tabular}{|c|c|c|c|c|c|c|c|c|c|c|c|c|}
\hline \multirow[b]{2}{*}{ Day } & \multicolumn{4}{|c|}{ Active-active } & \multicolumn{4}{|c|}{ Active-inactive } & \multicolumn{4}{|c|}{ Inactive-inactive } \\
\hline & $\mathrm{R} 1$ & $\mathrm{R} 2$ & R3 & $\mathrm{R} 4$ & $\mathrm{R} 1$ & R2 & R3 & $\overline{\mathrm{R} 4}$ & $\overline{\mathrm{R} 1}$ & $\mathrm{R} 2$ & R3 & $\mathrm{R} 4$ \\
\hline 1 & 0 & 0 & 0 & 0 & 0 & 0 & 0 & 0 & 0 & 0 & 0 & 0 \\
\hline 2 & 0 & 0 & 0 & 0 & 0 & 0 & 0 & 0 & 0 & 0 & 0 & 0 \\
\hline 3 & 0 & 0 & 0 & 0 & 0 & 0 & 0 & 0 & 0 & 0 & 0 & 0 \\
\hline 4 & 0 & $\mathrm{~h}$ & 0 & 1 & 0 & 0 & 0 & 0 & 0 & 0 & 0 & 0 \\
\hline 5 & $\mathrm{~h}$ & 1 & $1 \mathrm{~s}$ & 1 & 0 & 0 & 0 & 0 & 0 & 0 & 0 & 0 \\
\hline 6 & 1 & $1 \mathrm{~s}$ & $1 \mathrm{~s}$ & 1 & 0 & 0 & 0 & 0 & 0 & 0 & 0 & 0 \\
\hline 7 & $1 \mathrm{~s}$ & $1 \mathrm{~s}$ & 1 & 1 & 0 & 0 & 0 & 0 & 0 & 0 & 0 & 0 \\
\hline 8 & 1 & 1 & 1 & 1 & 1 & 1 & 1 & 1 & 0 & 0 & 0 & 0 \\
\hline 9 & 1 & 1 & 1 & 1 & 1 & 1 & 0 & 1 & 0 & 0 & 0 & 1 \\
\hline 10 & 1 & 1 & 1 & 1 & 1 & 1 & 1 & 1 & 1 & 1 & 1 & 1 \\
\hline 11 & 1 & 1 & 1 & 1 & 1 & 1 & 1 & 1 & 0 & 0 & 0 & 1 \\
\hline 12 & 1 & 1 & 1 & 1 & 1 & 1 & 1 & 1 & 1 & 1 & 1 & 1 \\
\hline 13 & 1 & 1 & 1 & 1 & 1 & 1 & 1 & 1 & 1 & 1 & 1 & 1 \\
\hline 14 & 1 & 1 & 1 & 1 & 1 & 1 & 1 & 1 & 1 & 1 & 1 & 1 \\
\hline 15 & 1 & 1 & 1 & 1 & 1 & 1 & 1 & 1 & 1 & 1 & 1 & 1 \\
\hline 16 & 1 & 1 & 1 & 1 & 1 & 1 & 1 & 1 & 1 & 1 & 1 & 1 \\
\hline
\end{tabular}

Note: 0 , no observation; 1 , presence of structures; $h$, intercellular hyphae only; s, possible single arbuscules.

arbuscules were often at different stages of metabolic development.

Visual observation of all arbuscular pairs in cortical cells of L. usitatissimum roots indicated that one side was typically larger than the other, even when both sides were newly developed and metabolically active (Fig. 1a). After 3 days of colonization, an inactive side (stained pink) appeared collapsed, while the metabolically active side (purple) was not (Fig. 1b). Even when paired structures appeared inactive but were attached to an active intercellular hypha (Fig. 1c), there was still a visible size difference between them. The hypha adjoining these two arbuscules typically shows small, active, finger-like projections. In metabolically inactive pairs, observations were often difficult due to a lack of staining in the most highly collapsed structures (Fig. 1d). The position of the pairs within the colonization unit did not influence the order in which they developed. There was no indication that the older arbuscule was always nearest the entry point or the youngest nearest the colonizing front.

Under confocal microscopy, the double-stained arbuscules showed different intensities of fluorescence depending on their metabolic activity. In general, metabolically inactive structures fluoresced more brightly under the confocal settings used. The finger-like projections observed between the paired structures were also highly fluorescent in the majority of images. These projections, although observed in all L. usitatissimum cultivars, appeared to differ slightly in structure between the fungal species, for example, Glomus mosseae and Gigaspora rosea (Figs. $2 a$ and $2 b$, respectively).

\section{Development of paired arbuscules showing metabolic activity}

The development and senescence of paired arbuscules over time and their metabolic status are shown in Table 1. In the nurse tray system, some plants became colonized at
4 days after transplanting, forming intercellular hyphae or intercellular hyphae plus arbuscules. During the early stage of development, some single active arbuscules were observed. By 8 days, in paired arbuscules, one of the pair was showing loss of succinate dehydrogenase activity, while the other remained active (i.e., the paired structure was activeinactive). At 9 days, some entire pairs were no longer active. From 9 to 16 days, all combinations of metabolic activity in the pairs (i.e., active-active, active-inactive, and inactiveinactive) were recorded. Cross walls were observed in the trunk hypha of some arbuscules separating an inactive arbuscule from the trunk hypha and its metabolically active partner (Fig. 3).

\section{Statistical results}

Logistic regression estimated the probability of finding paired arbuscules at a given stage of metabolic activity on a given day (Fig. 4). The value 0 shows that the observation yielded a negative result (i.e., no arbuscules with the selected activity grouping were observed in that sample on that day) and the value 1 a positive observation. The thick line in each graph gives the estimated probability of each event and the thin lines the $95 \%$ confidence limits. The little overlap in confidence limits between the graphs (active-active, activeinactive and, inactive-inactive) indicates that there is a sequence in development and that the probabilities of observing each activity stage of paired arbuscules between 2 and 12 days are different. The statistical results suggest that the individual arbuscules are metabolically active for about 4 days.

\section{Volume and surface area of the paired arbuscules}

The volume and surface area of each arbuscule in a developing paired structure were measured to estimate the difference in size between them. A montage was created from a series of optical slices taken at $2.13-\mu \mathrm{m}$ intervals on the 
Fig. 1. Longitudinally orientated paired arbuscules in cortical cells of Linum usitatissimum roots colonized by Glomus intraradices. (a) Metabolically active paired structure (purple-purple); (b) one metabolically active side and other inactive (purple-pink); (c) two inactive arbuscules with active subtending intercellular hypha; $(d)$ inactive pair showing lack of uptake of stain (pink-pink/clear). The arrow shows the direction of the root tip. Scale bar $=20 \mu \mathrm{m}$ for all images.

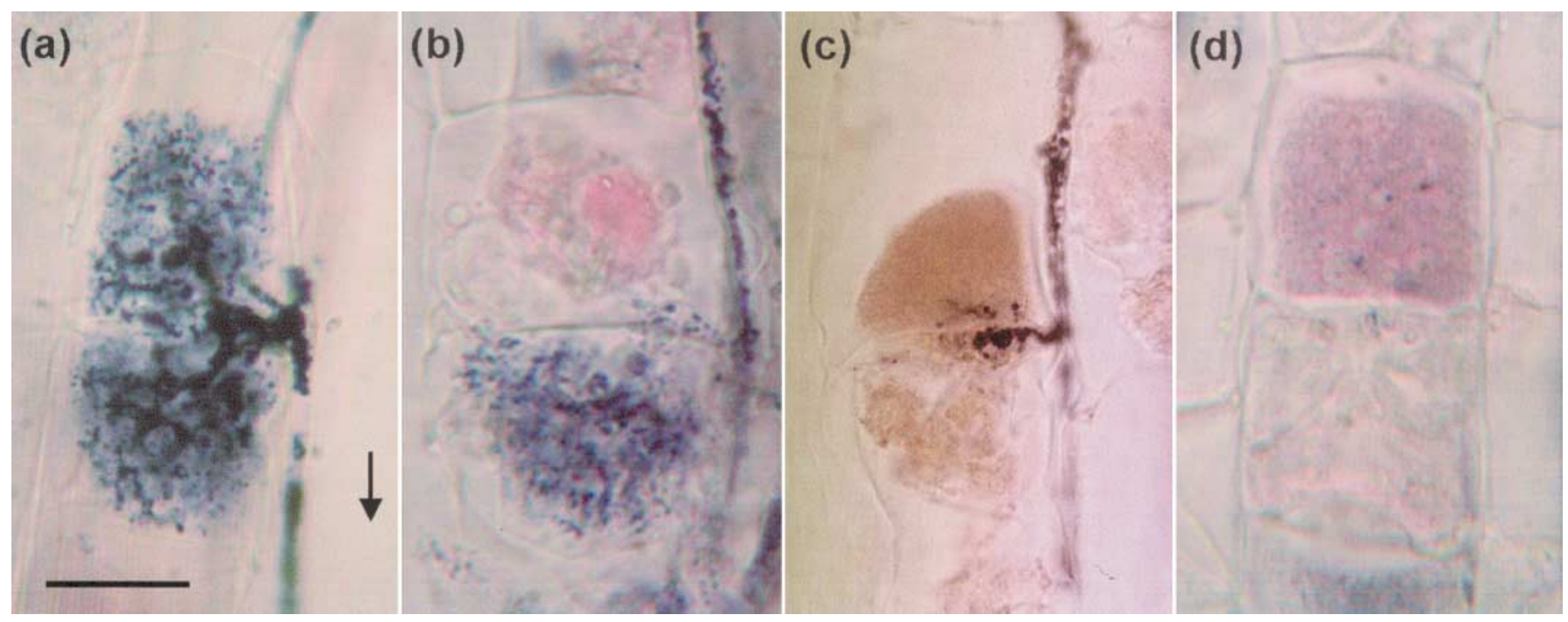

Fig. 2. Confocal micrographs of the finger-like projections (arrowed) produced by (a) Glomus mosseae and (b) Gigaspora rosea in Linum usitatissimum. Scale bar $=10 \mu \mathrm{m}$.

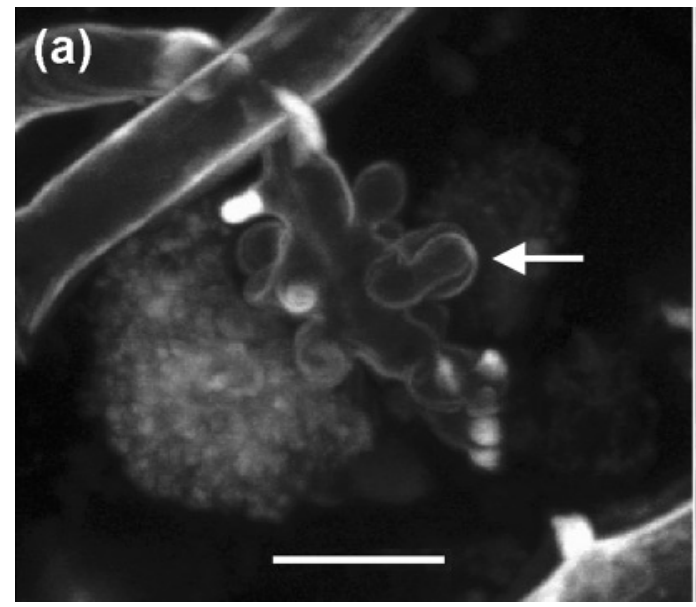

Fig. 3. Cross wall in the trunk hypha of the metabolically inactive arbuscule (arrowed) in an arbuscular pair. Scale bar $=15 \mu \mathrm{m}$.

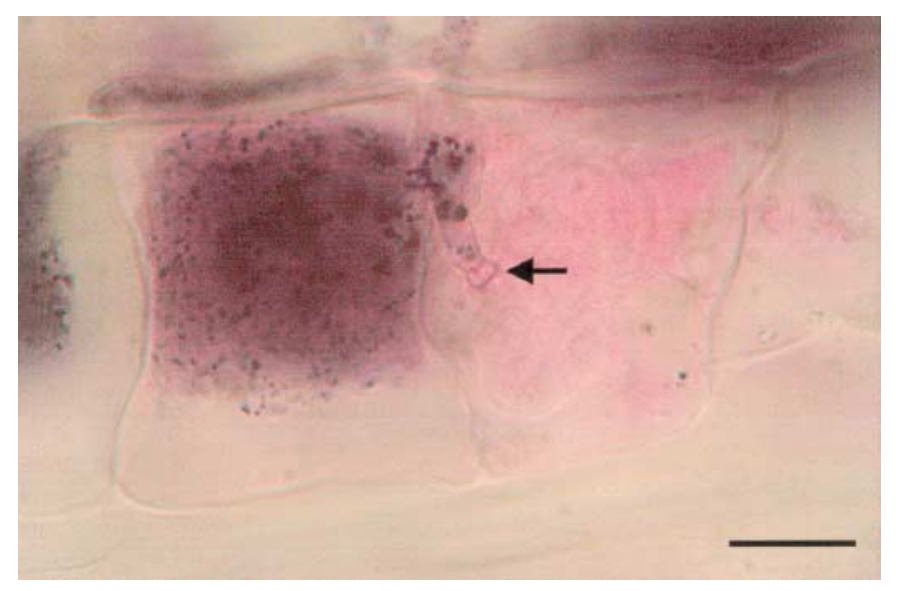

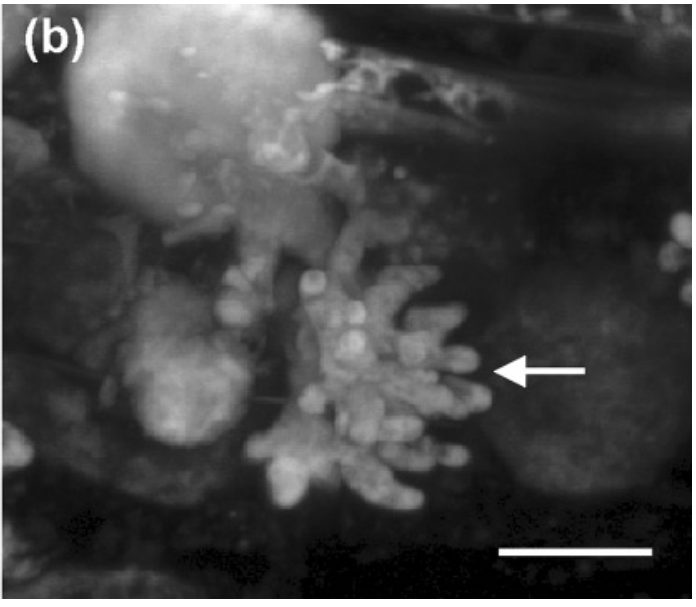

$z$-axis through a metabolically active pair of arbuscules produced by Glomus intraradices in L. usitatissimum cv. Eyre (Figs. $5 a-5 g$ ). All 24 optical slices taken at $0.71-\mu \mathrm{m}$ intervals were used to produce the extended focus image (Fig. 5h). The volume measurement and surface area estimation of this structure for the larger arbuscule were $2628 \mu^{3}$ and $4821 \mu^{2}$, respectively, and for the smaller one were $1596{\mu \mathrm{m}^{3}}^{3}$ and $3592 \mu \mathrm{m}^{2}$, respectively.

\section{Discussion}

These results show clearly that the structure of Arum-type mycorrhizal colonization can be more complex than previously described. In L. usitatissimum, a range of AM fungi produced arbuscules that, instead of being singular terminal structures, were in fact paired structures positioned in two adjacent, longitudinally arrayed cortical cells. Double staining showed that these paired arbuscules were often at differ- 
Fig. 4. Logistic regression of paired arbuscules at a given stage of metabolic activity on a given day. (a) Active-active; (b) active-inactive; $(c)$ inactive-inactive. Thick line, estimated probability of each event; thin lines, $95 \%$ confidence limits.
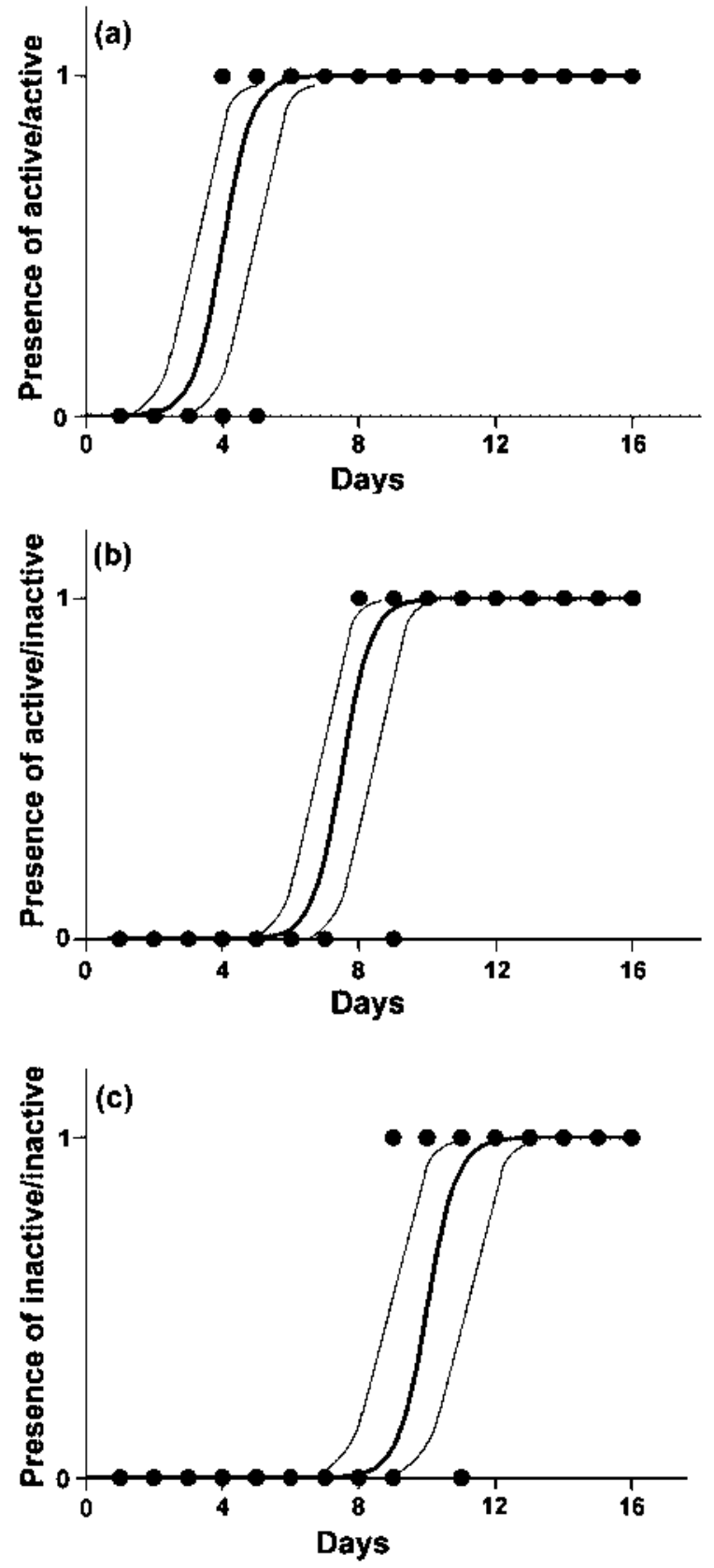

ent stages of development. This indicates that either the rates of structural formation between the two arbuscules varied or one arbuscule developed prior to the penetration of the fungus into the neighbouring cortical cell. Single arbuscules were occasionally observed in the early stages of the time course experiment, indicating that a time delay in the formation of the second structure is possible. These single arbuscules may, however, have been observed because material was not always cut parallel to the cell layers. Nevertheless, the loss of metabolic activity of one structure within the pair strongly indicates that the arbuscules differ in their time of initiation. The collecting of optical sections and subse- quent measurement of the surface area of metabolically active paired arbuscules also support this. When observing sequential confocal slices, one arbuscule appeared first and remained visible after the disappearance of the second; the arbuscule observed in the fewer confocal slices had only $61 \%$ of the volume and $75 \%$ of the surface area of the visually larger structure. The volume and surface area estimates of these arbuscules are in the same range as those of arbuscules of Glomus coronatum (formally ' $G$. City Beach') measured in Allium porrum (Dickson 1999; Dickson and Kolesik 1999).

The results of the statistical analyses together with daily observations indicate that these arbuscules are metabolically active for about 4 days and that the age difference between the two members of the pair is unlikely to be more than 12 days. The life span of these paired arbuscules does not appear to be different from those seen in "ordinary" Arumtype colonization in Allium cepa or Allium porrum (Cox and Tinker 1976; Dickson and Smith 2001).

Arbuscules fluoresced at different levels of intensity depending on their metabolic activity. Stained arbuscules that appeared pale pink or clear and were metabolically inactive generally fluoresced more brightly than those that were purple. Collapsed arbuscules have been shown to autofluoresce strongly (Ames et al. 1982; Jabaji-Hare et al. 1984, 1985; Vierheilig et al. 1999, 2001). However, acid fuchsin staining has also been used to produce bright fluorescence under confocal conditions (Merryweather and Fitter 1991; Dickson and Kolesik 1999). The differences in fluorescence in the paired arbuscules in this study may be due to the lower uptake of acid fuchsin in active structures because of prestaining with succinate dehydrogenase solution or due to fluorescence quenching by the formazan precipitate. The formation of the radial finger-like projections observed between the arbuscular pairs, often highly fluorescent, requires more investigation as to whether these structures are in fact within the cortical cells or are in the intercellular spaces.

Time course observations have indicated the presence of cross walls in the paired arbuscules (see Fig. 3). This has yet to be fully examined in an extensive study. The presence of a cross wall in the trunk hypha of single metabolically inactive arbuscules has previously been shown in Allium porrum (Dickson and Smith 2001). It would be logical to assume that a nonfunctioning arbuscule within a paired system might also be sealed off, especially if the intercellular hypha connecting the two sides is still active.

The dimensions and continuity of airspaces between root cortical cells are believed to play important roles in determining whether a plant forms Arum- or Paris-type AM (Brundrett and Kendrick 1988, 1990; Cavagnaro et al. $2001 b$ ). Preliminary investigations using an apoplastic dye (Sulphorhodamine G) indicate that in roots of L. usitatissimum, longitudinal spaces were continuous for only short distances and that spaces could be observed between adjacent cortical cells (F.A. Smith and S. Dickson, personal communication). This pattern of development is quite different from those in Allium porrum, a typical Arumtype plant, in which longitudinal airspaces are continuous for long distances. Differences may depend on the way in which the meristematic cells divide during the development of the inner cortex. In Linum, "The inner layer [of the 
Fig. $5(a-g)$. Montage of a series of optical slices taken at $2.13-\mu \mathrm{m}$ intervals on the $z$-axis through a metabolically active pair of arbuscules produced by Glomus intraradices in Linum usitatissimum cv. Eyre; $(h)$ extended focus image (24 optical slices at $0.71-\mu \mathrm{m}$ intervals). Scale bar $=10 \mu \mathrm{m}$ for all images.
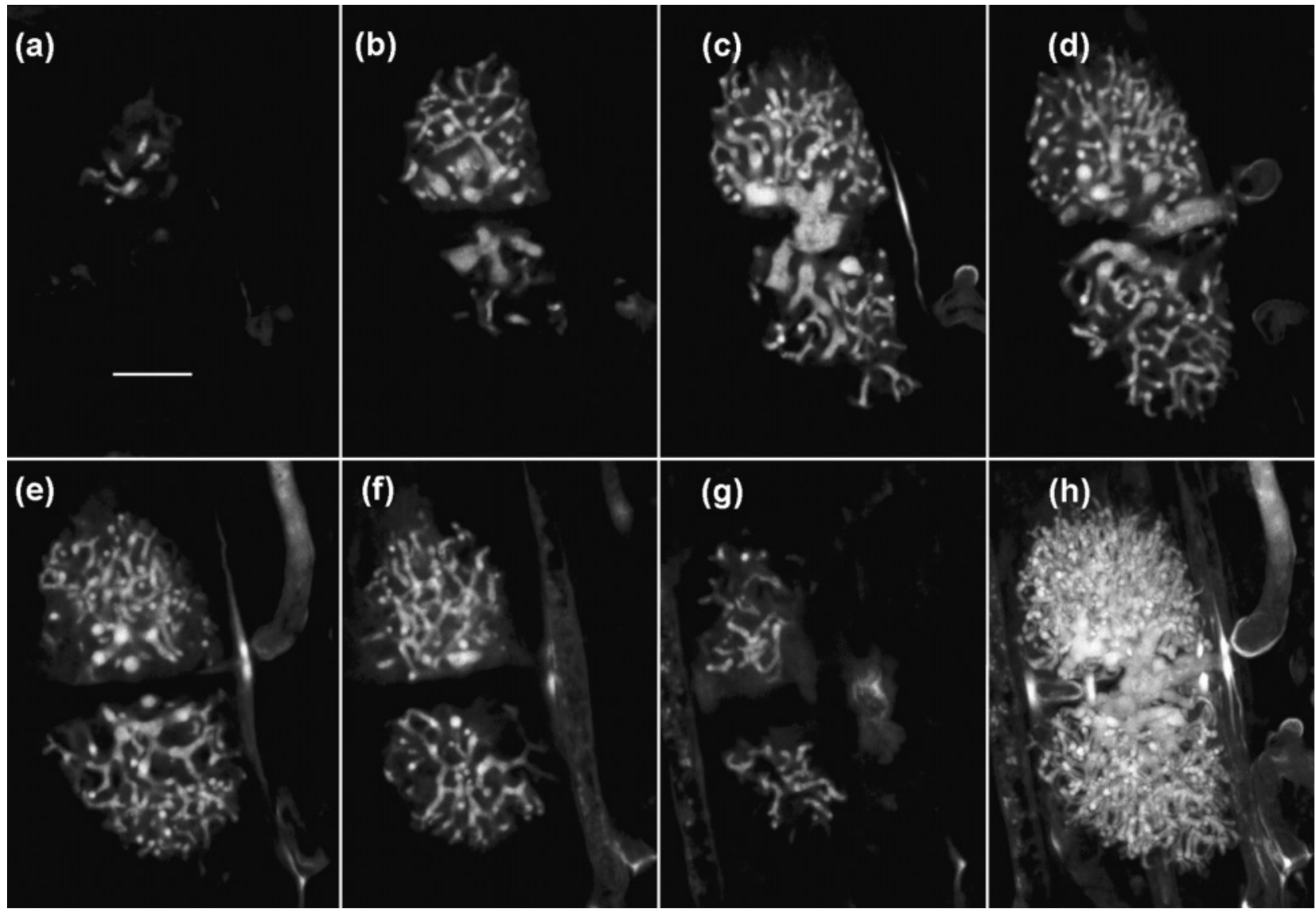

periblem] divides in all planes and forms the remainder of the cortex, which at maturity is about 6-9 cells in thickness" (Crooks 1933). This may result in more tortuous airspaces and hence be the reason why the intercellular hyphae appear to be discontinuous. In transverse section, intercellular hyphae would occur in some of the airspaces adjacent to arbuscules, and in this plane the paired occurrence of arbuscules would not be observed. In longitudinal section, both intercellular hyphae and paired arbuscules in various stages of development would be apparent. Our findings emphasize that details of AM fungal morphology can only be fully appreciated in the context of patterns of root cell development and orientation of samples.

In conclusion, the use of $L$. usitatissimum as a host plant will be advantageous in future investigations by allowing the comparison of cellular processes between mycorrhizal structures of slightly different metabolic activities in adjacent cortical cells.

\section{Acknowledgements}

We wish to thank Drs. E. and J. Facelli for statistical analyses, the Australian Research Council for financial support, and the Australian Research Council International Researcher Exchange Program for the funding of research visits to Adelaide (P.S.) and Lund (S.D.).

\section{References}

Alexander, T., Meier, R., Toth, R., and Weber, H.C. 1988. Dynamics of arbuscule development and degeneration in mycorrhizas of Triticum aestivum L., and Avena sativa L. with reference to Zea mays L. New Phytol. 110: 363-370.

Ames, R.N., Ingham, E.R., and Reid, C.P.P. 1982. Ultravioletinduced autofluorescence of arbuscular mycorrhizal root infections: an alternative to clearing and staining methods for assessing infections. Can. J. Microbiol. 28: 351-355.

Brundrett, M.C., and Kendrick, B. 1988. The mycorrhizal status, root anatomy, and phenology of plants in a sugar maple forest. Can. J. Bot. 66: 1153-1173.

Brundrett, M., and Kendrick, B. 1990. The roots and mycorrhizas of herbaceous woodland plants. II. Structural aspects of morphology. New Phytol. 114: 469-479.

Brundrett, M.C., Piché, Y., and Peterson, R.L. 1985. A developmental study of the early stages in vesicular-arbuscular mycorrhiza development. Can. J. Bot. 63: 184-194.

Cavagnaro, T.R., Gao, L-L., Smith, F.A., and Smith, S.E. $2001 a$. Morphology of arbuscular mycorrhizas is influenced by fungal identity. New Phytol. 151: 469-475.

Cavagnaro, T.R., Smith, F.A., Lorimer, M.F., Haskard, K.A., Ayling, S.M., and Smith, S.E. 2001b. Quantitative development of Paris-type arbuscular mycorrhizas formed between Asphodelus fistulosus and Glomus coronatum. New Phytol. 149: 105-113.

Cooke, M.A, Widden, P., and O'Halloran, I. 1993. Development of 
vesicular-arbuscular mycorrhizae in sugar maple (Acer saccharum) and effects of base-cation amendment on vesicle and arbuscule formation. Can. J. Bot. 71: 1421-1426.

Cox, G., and Tinker, P.B. 1976. Translocation and transfer of nutrients in vesicular-arbuscular mycorrhizas. I. The arbuscule and phosphorus transfer: a quantitative ultrastructural study. New Phytol. 77: 371-378.

Crooks, D.M. 1933. Histological and regenerative studies on the flax seedling. Bot. Gaz. 95: 209-239.

Dickson, S. 1999. Phosphate transfer efficiency of two arbuscular mycorrhizal fungi. Ph. D. thesis. Department of Soil and Water, University of Adelaide, South Australia, Australia.

Dickson, S., and Kolesik, P. 1999. Visualization of mycorrhizal fungal structures and quantification of their surface area and volume using laser scanning confocal microscopy. Mycorrhiza, 9: $205-213$.

Dickson, S., and Smith, S.E. 2001. Cross walls in arbuscular trunk hyphae form after loss of metabolic activity. New Phytol. 151: 735-742.

Dickson, S., Smith, S.E., and Smith, F.A. 1999. Characterization of two arbuscular mycorrhizal fungi in symbiosis with Allium porrum: inflow and flux of phosphate across the symbiotic interface. New Phytol. 144: 173-181.

Gallaud, I. 1905. Études sur les mycorrhizes endotrophs. Rev. Gen. Bot. 17: 5-48, 66-83, 123-135, 223-239, 313-325, 425-433, 479-500.

Jabaji-Hare, S.H., Perumalla, C.J., and Kendrick, W.B. 1984. Autofluorescence of vesicles, arbuscules, and intercellular hyphae of a vesicular-arbuscular fungus in leek (Allium porrum) roots. Can. J. Bot. 62: 2665-2669.

Jabaji-Hare, S., Perumalla, C.J., and Kendrick, W.B. 1985. Autofluorescence of a vesicular-arbuscular mycorrhizal fungus in Allium porrum. In Proceedings of 6th North American Conference on Mycorrhizae, Bend, Oregon, U.S.A., June 25-29, 1984. Edited by R. Molina. Forest Research Laboratory, Oregon State University, Corvallis, Oreg. p. 380.

Kormanik, P.P., and McGraw, A.C. 1982. Quantification of vesiculararbuscular mycorrhizae in plant roots. In Methods and principles of mycorrhizal research. Edited by N.C. Schenck. American Phytopathological Society, St. Paul, Minn. pp. 37-45.

Kough, J.L., Gianinazzi-Pearson, V., and Gianinazzi, S. 1987. Depressed metabolic activity of vesicular-arbuscular mycorrhizal fungi after fungicide applications. New Phytol. 106: 707-715.
Merryweather, J.W., and Fitter, A.H. 1991. A modified method for elucidating the structure of the fungal partner in a vesiculararbuscular mycorrhiza. Mycol. Res. 95: 1435-1437.

Rosewarne, G.M., Barker, S.J., and Smith, S.E. 1997. Production of near-synchronous fungal colonization in tomato for developmental and molecular analyses of mycorrhiza. Mycol. Res. 101: 966-970.

Schaffer, G.F., and Peterson, R.L. 1993. Modifications to clearing methods used in combination with vital staining of roots colonized with vesicular-arbuscular mycorrhizal fungi. Mycorrhiza, 4: 29-35.

Smith, F.A., and Smith, S.E. 1997. Structural diversity in (vesicular)arbuscular mycorrhizal symbiosis. New Phytol. 137: 373-388.

Smith, S.E., and Dickson, S. 1991. Quantification of active vesicular-arbuscular mycorrhizal infection using image analysis and other techniques. Aust. J. Plant Physiol. 18: 637-648.

Smith, S.E., and Read, D.J. 1997. Mycorrhizal symbiosis. 2nd ed. Academic Press, Cambridge, U.K.

Smith, S.E., Dickson, S., Morris, C., and Smith, F.A. 1994. Transport of phosphate from fungus to plant in VA mycorrhizas: calculation of the area of symbiotic interface and of fluxes of $\mathrm{P}$ from two different fungi to Allium porrum L. New Phytol. 127: 93-99.

Toth, R., and Miller, R.M. 1984. Dynamics of arbuscule development and degeneration in a Zea mays mycorrhiza. Am. J. Bot. 71: 449-460.

Vierheilig, H., Böckenoff, A., Knoblauch, M., Juge, C., van Bel, A.J.E., Grundler, F., Piché, Y., and Wyss, U. 1999. In vivo observations of the arbuscular mycorrhizal fungus Glomus mosseae in roots by confocal laser scanning microscopy. Mycol. Res. 103: 311-314.

Vierheilig, H., Knoblauch, M., Juergensen, K., van Bel, A.J.E., Grundler, F.M.W., and Piché, Y. 2001. Imaging arbuscular mycorrhizal structures in living roots of Nicotiana tabacum by light, epifluorescence, and confocal laser scanning microscopy. Can. J. Bot. 79: 231-237.

Whitbread, F., McGonigle, T.P., and Peterson, R.L. 1996. Vesicular-arbuscular mycorrhizal associations of American ginseng (Panax quinquefolius) in commercial production. Can. J. Bot. 74: 1104-1112. 